\title{
Direct electroplating of plastic for advanced electrical applications
}

\author{
Islam, Aminul; Hansen, Hans Nørgaard; Tang, Peter Torben
}

\section{Published in:}

C I R P Annals

Link to article, DOI:

10.1016/j.cirp.2017.04.124

Publication date:

2017

Document Version

Peer reviewed version

Link back to DTU Orbit

Citation (APA):

Islam, A., Hansen, H. N., \& Tang, P. T. (2017). Direct electroplating of plastic for advanced electrical applications. C I R P Annals, 66(1), 209-212. https://doi.org/10.1016/j.cirp.2017.04.124

\section{General rights}

Copyright and moral rights for the publications made accessible in the public portal are retained by the authors and/or other copyright owners and it is a condition of accessing publications that users recognise and abide by the legal requirements associated with these rights.

- Users may download and print one copy of any publication from the public portal for the purpose of private study or research.

- You may not further distribute the material or use it for any profit-making activity or commercial gain

- You may freely distribute the URL identifying the publication in the public portal

If you believe that this document breaches copyright please contact us providing details, and we will remove access to the work immediately and investigate your claim. 


\title{
Direct electroplating of plastic for advanced electrical applications
}

\author{
Aminul Islam a, b, , Hans Nørgaard Hansen (1) ${ }^{\mathrm{b}}$, Peter Torben Tang c \\ ${ }^{a}$ Centre for Acoustic-Mechanical Micro Systems, Technical University of Denmark, Lyngby, Denmark \\ ${ }^{b}$ Department of Mechanical Engineering, Technical University of Denmark, Lyngby, Denmark \\ cIPU, Lyngby, Denmark
}

\begin{abstract}
Electrodeposition or electroplating is predominantly applied to metallic components. Electroplating of plastics is possible in some cases where an initial electroless plating layer of nickel or copper is made to provide a conductive surface on the plastic part. This paper proposes a method for direct electroplating of plastic eliminating the need for slow and expensive processes like electroless metal deposition, PVD coating, painting with conductive inks etc. The results obtained from the test demonstrate the potential of direct electroplating of plastic to enhance the electrical conductivity and the use of electroplated plastics for advanced applications like Moulded Interconnect Devices (MIDs).
\end{abstract}

Plastic composite, Surface analysis, Electroplating

\section{Introduction and motivation}

Electrically conductive plastics combine the properties of plastics with the properties of metals. They are easy to process, light weight, corrosion resistant, can be shaped by moulding; moreover they give the electrical conductivity needed for many applications. Some polymers can be naturally or intrinsically conductive like polyanilines, poly(pyrrole)s, poly(thiophene)s, polyphenylenes, etc. But plastics can also be artificially made conductive by doping or compounding technologies [1]. The focus of this paper is the plastics that are made artificially conductive, the so called conductive plastic composites. Different techniques are used to make plastic conductive like the addition of fillers such as carbon black, graphite, carbon nano-tubes, metallic fibers etc. [2]. These compounds are typically used in electrostatic discharge (ESD) control and electromagnetic interference (EMI) shielding applications [3]. In the near future, the modified electrically conductive plastics can be widely used in many other industrial applications like for the production of Moulded Interconnect Devices (MIDs), for antennas, solar cells, polymer based electronics, biosensors, LED lighting, touch sensors, polymer based MEMS devices, transistors and many more. Particularly the MIDs show enormous potential in using electrically conductive polymers, due to the adaption of conductive patterns to the geometric form of the products [4]. But before the electrically conductive plastics can be used in such wide spread applications, there are some technical challenges to overcome. One of these is the achievable electrical conductivity of the composites [5]. It is possible to produce highly complex 3D conductive elements by injection moulding from conductive composites, but the offered conductivity is not as good as it is required for many applications. One example of such is demonstrated in [6] with an FM antenna for hearing aids. Currently available electrically conductive composites are unable to fulfil the future demands and when it comes to the point of thin-walled or miniaturized components, so far conductive plastics have nothing to offer as the conductivity of the material is drastically reduced due to smaller dimensions [5]. In this paper, a novel method for the direct electroplating of plastics is proposed. The proposed method can significantly improve the electrical conductivity of the poorly conductive plastic composite.

\section{Materials and methods}

To select a mouldable and highly conductive plastic composite, an extensive search was made in material data bases and also in the literature. The final selection was Schulatec TinCo 50 from A. Schulman Inc, Akron, USA which showed the highest electrical conductivity among the available options and also good mechanical properties. This material consists of 15 wt.\% (56 vol.\%) Polyamide 6 (PA6), 52 wt.\% of fine copper fibres (average length $0.65 \mathrm{~mm}$, diameter $35 \mu \mathrm{m}$ ) and $33 \mathrm{wt} . \%$ of a low-melting Tin/Zinc alloy $\left(199^{\circ} \mathrm{C}\right.$ ) ) [5]. Fig. 1 shows the commercially available granulates of the selected material (picture A). The Tin/Zinc alloy in the material becomes liquid during the processing phase (e.g. moulding) and makes the connection among the long copper fibers, and that is how the material makes a conducting network of metallic components in the plastic matrix (schematically presented in picture B of Fig. 1).

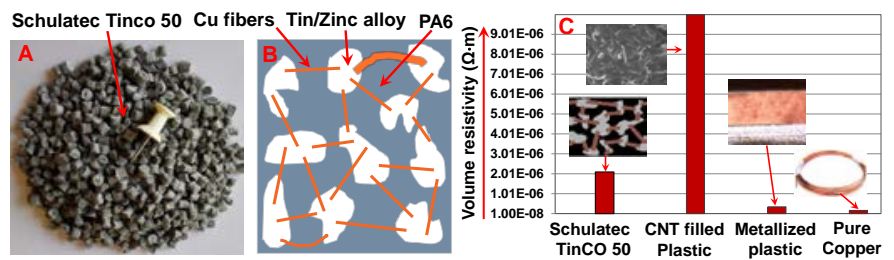

Figure 1. Granulates of Schulatec TinCo 50 (A), schematic representation of conductive network inside moulded parts (B), comparative resistivity (approximate) of Schulatec TinCo 50 compared with other materials (C).

Fig. 2 presents the results from the morphological investigation done with the moulded parts of the material. The analysis was done with the help of an Alicona Infinite Focus microscope and Scanning Probe Image Processor (SPIP) version 6.6.1. Picture C of Fig. 2 was taken at the cross section of a moulded sample. The copper fibers are clearly visible in the cross section which are connected by the tin/zinc alloy (white colour substance) to some extent. In this way the copper fibers and the alloys are forming a conductive network of metallic materials inside the polymer matrix. Many disconnections among the neighbouring fibres are visible too. This proves that a theoretical continuous network of copper fibers (as presented in picture B of Fig. 1) is not possible. It is characterized by a combination of continuous and discontinuous fiber networks in the polymer matrix. The morphological analysis at the cross section revealed that about $21 \%$ area was covered with copper (yellow substance in picture E), about $17 \%$ area was covered by tin-zinc alloy (grey in picture F) and the rest was the plastic material-PA6 (black in picture D). 


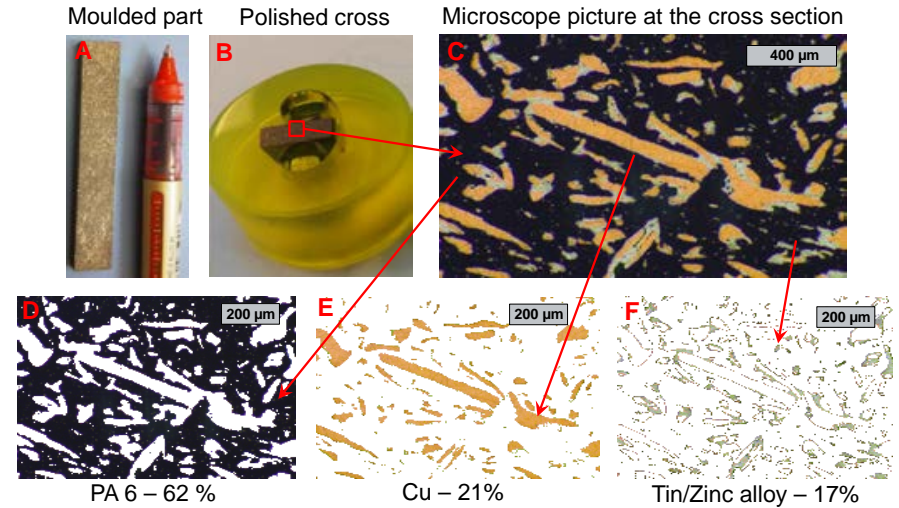

Figure 2. Moulded specimen (A), Sample prepared microscopic investigation (B), optical microscope image at the part cross section (C), material analysis results for PA 6 (D), Cu (E) and Tin/Zinc alloy (F).

Schulatec TinCo 50 is a non-homogeneous mixture (can also be seen in Fig. 2) that has no defined conductive direction. For the material, the manufacturer claims a conductivity of $5 \times 10^{5} \mathrm{~S} / \mathrm{m} \mathrm{[7]}$ (volume resistivity of $2.00 \times 10^{-4} \Omega-\mathrm{m}$ ). It is important to note that detailed studies about similar materials report that the conductivity values are susceptible to the injection moulding conditions such as: mould temperature, distance from the injection gate, flow direction, part geometry, dimension etc. $[5,7$, 8]. Nevertheless, the electrical conductivity of Schulatec TinCo 50 is among the highest ranking conductive composites. The comparative volume resistivity of Schulatec TinCo 50 is presented in the Fig. 1 (picture C). The resistivity is significantly lower than other commercially available conductive plastics like Plasticyl PA 1501 which is Polyamide (PA66) filled with $15 \mathrm{wt} \%$ Carbon Nano Tubes (CNTs). But the resistivity of Schulatec TinCo 50 it is still many times higher than pure copper or metallized plastics (with copper). This is the problem for many current and future applications as discussed before. The following experimental process and results will show one way to enhance the electrical conductivity of the plastic composite to help the wide spared applications of conductive plastics for the production of electromechanical components.

\section{Electroplating experiments and results}

To enhance the electrical conductivity of parts moulded with Schulatec TinCo 50, an electroplating process was applied. The most widely used metallization process for plastics is an electroless process which is characterized by being a slow, chemical intensive process involving many different process steps [9]. The electroless process is toxic especially the etching solution that consists of a hot balanced mixture of chromic acid, sulfuric acid, and water [10]. The introduction of these chemicals to a production chain raises huge environmental and safety concerns. The direct electroplating of plastics can overcome most of these problems. Electroplating is primarily used to change the surface properties of an object (e.g. abrasion and wear resistance, corrosion protection, aesthetic qualities, etc. [10]). But this can be beneficial also for the global conductivity of the material as it can create a highly conductive surface layer. The presences of some degree of conductivity in Schulatec TinCo 50, suggests that direct plating of the material can be a possibility. This attempt has never been reported before according to the material supplier [7]. When electroplating is attempted for plastics, usually a thin initial layer of metal is deposited on the surface by process like electroless metal deposition, conductive painting or PVD coating etc. But the use of the electrically conductive plastic as in the current case will eliminate the need of any secondary processes to make the preliminary conductive surface.

For the electroplating experiment, the injection moulded test specimen (shown in Fig. 2 - picture A) made with Schulatec TinCo 50 were connected to cathode terminal of the plating bath and the anode was pure copper $(\mathrm{Cu})$ electrode. The plating bath was an acidic copper bath based on sulphuric acid and copper sulphate. During the first trial of the plating, the used current supply was 3 $\mathrm{A} / \mathrm{dm}^{2}$ and the plating time set was 6 mins. The result of the initial trial of the electroplating is shown in Fig. 3 (picture A, B and $\mathrm{C}$ ). Some plating of $\mathrm{Cu}$ on some selective areas of the part surface was visible but most of the area was uncovered. As the current and plating time are the main parameters for the electroplating, several trial and error steps were carried out to find some optimized plating conditions by changing time and current. A current density of $8 \mathrm{~A} / \mathrm{dm}^{2}$ plating time of 11 minutes were found as the most optimized condition for the electroplating trial. But even with these plating conditions, the metallic coverage was not good. About $12 \%$ areas of test parts were covered with metal and rest of the areas were uncovered.
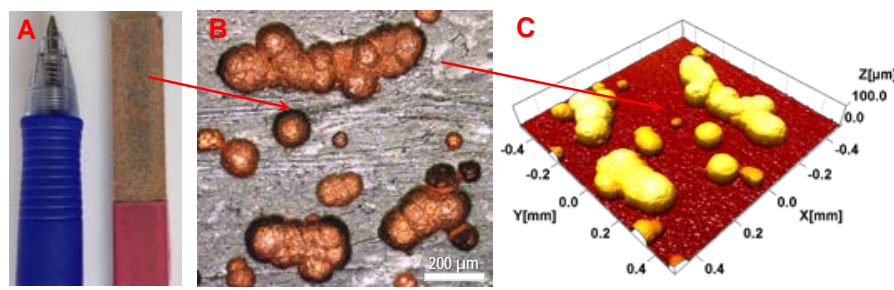

Part after plating Micrograph: Electroplated surface 3D Image: Electroplated surface

Figure 3. Part after plating (A), optical microscope picture of the electroplated surface (B) and 3D profile image of the surface (C).

To find the reason for poor coverage of the surface after electroplating, the moulded part was subjected to microscopic investigation. Fig. 4 (picture A) shows a magnified view of a part surface before electroplating, where some metallic materials (fibers) are visible on the surface but the amount is low. An analysis of the surface with Alicona and SPIP showed about $7 \%$ surface area was covered by the metallic fibers and rest of the area was basically plastic material. A close look to the exposed metallic fibers showed that even the area that was covered by metallic fiver was having a thin layer of plastic material over the metal fibers (about 5 to $10 \mu \mathrm{m}$ thick). This thin plastic layer was the so called skin layer formed by plastic moulding process. The presence of this thin plastic layer between the metal fibers and electroplated metal hindered the adhesion of the plated metal and it did not pass the tape test (could be easily removed by adhesive tape). The tape test performed was similar to the procedure describe in IPC-TM-650 [11].

To increase the metallic coverage by electroplating process different surface treatment techniques like milling, sand paper grinding and wet abrasive blasting (wetblasting) were used. Basically, with these processes some material from the part surface was removed to expose more metallic fibers. By the milling, about $0.1 \mathrm{~mm}$ of material was removed from the surface using a rotary cutter. During sand paper grinding, 80 grit size papers was used to remove about $0.1 \mathrm{~mm}$ surface layer. For the wetblasting process a mixture of water and abrasive $\left(\mathrm{Al}_{2} \mathrm{O}_{3}\right.$ powder) was propelled via a blast nozzle to remove the skin layer from the part surface. The equipment used was Vapormate 3 from Vapormatt Ltd, UK. Approximately $0.1 \mathrm{~mm}$ thick layer of material was removed by the blasting process. The changes made by different surface treatment can be seen in the picture B, C and $\mathrm{D}$ of Fig. 4 in comparison with the original surface shown in 
picture A. The surface treated parts had higher amount of metal fibers exposed to the surface compared to the original moulded surface. Fig. 4 (picture G) shows the metallic fibres spiking out from the surface treated part and picture $\mathrm{E}$ and $\mathrm{F}$ show the macroscopic difference made by surface treatment (wetblasting).

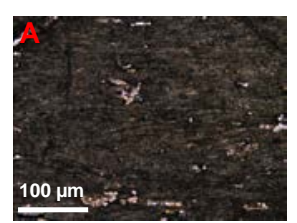

Moulded surface

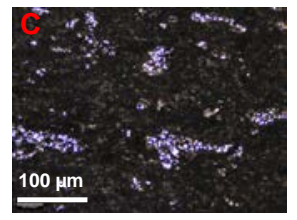

Grinded surface

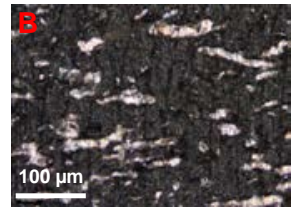

Milled surface

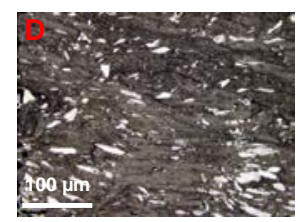

Wetblasted surface

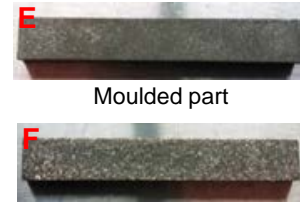

Surface treated part

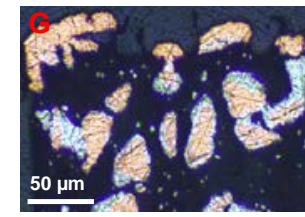

Wetblasted - fibers exposed
Figure 4. Surfaces of the moulded Schulatec TinCo 50 parts modified by different surface treatment techniques.

After the surface treatments, the treated parts were exposed to the electroplating using the optimum conditions selected during the initial trial. The results showed significant improvement on the coverage of the plated metal, nevertheless, the metallic coverage was not $100 \%$. Fig. 5 shows the comparative pictures (A, B and C) of the plated surfaces with different surface treatment techniques.

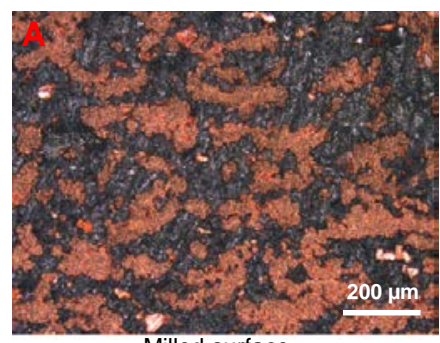

Milled surface

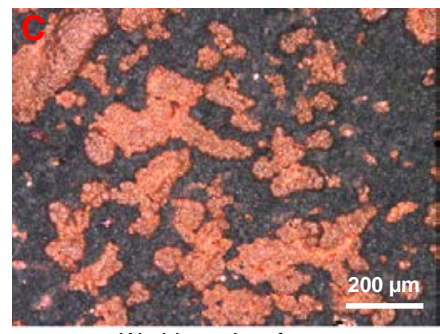

Wetblasted surface

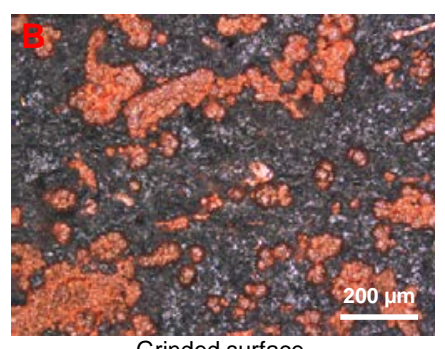

Grinded surface

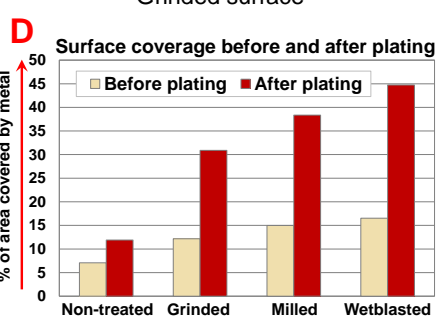

Comparative coverage plot
Figure 5. Electroplating results from various treated surfaces (Picture A, $B$ and $C$ ), improvement on the surface coverage after surface treatment and electroplating (plot D).

A SPIP analysis revealed that when the surface was untreated about $7 \%$ area was covered by metal before plating and after plating it was about $12 \%$. Different surface treatment techniques increase the metallic coverage on the surface of the parts both before and after electroplating (comparative results are presented in plot D of Fig. 5). The best results were obtained by the surface treatment with wetblasting. On the average, the wetblasted surface had about $17 \%$ metallic coverage before electroplating and after electroplating the coverage was about $45 \%$ which was a significant improvement. Besides the positive effect on the coverage, the surface treatments also had positive effects on the adhesion of the electroplated metal layers.
Fig. 6 (picture A) shows a cross sectional interface of deposited metal on the surface of a moulded part. Between the copper fiber and the metal layer, a gap is visible which basically is a thin layer of plastic. So in this case, the adhesion occurs between metal and plastic which is a weak adhesion. On the contrary, picture B of Fig. 6 reveals the adhesion mechanism in case of surface treated parts. By the surface treatment, the skin layer is removed. This is why metal-to-metal adhesion can occur which generates a strong bond [12]. Moreover, the increased average surface roughness by the surface treatments also had positive effects on the adhesion of electroplated metal on the part surface. The electrodeposited metal on the surface treated parts passed the tape test (it was not possible to remove the metal with the tape).
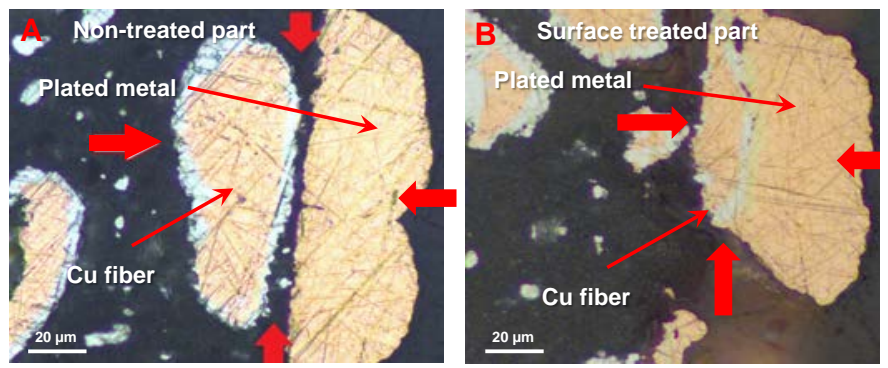

Figure 6. Adhesion mechanism of plated metal on treated and non-treated surfaces.

In connection with the electroplating process, a nickel (Ni) bath was also used for the plating. Ni plated surface offers excellent corrosion resistance, solderability and surface uniformity [13]. These aspects of $\mathrm{Ni}$ plating can be highly attractive for applications like in MIDs. The used $\mathrm{Ni}$ bath was a low-stress and low-speed bath based on nickel sulphamate and boric acid. The current density and the time used for this bath were same as optimized $\mathrm{Cu}$ bath (plating result shown in Fig. 7). The surface analysis of the $\mathrm{Ni}$ plated parts showed that the coverage of $\mathrm{Ni}$ was higher (about 64\% surface was covered) than previously $\mathrm{Cu}$ plated parts (maximum coverage obtained was about $45 \%$ ).

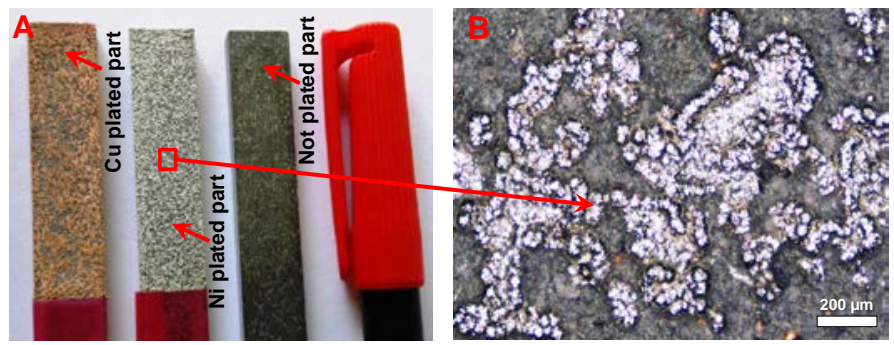

Figure 7. Picture of $\mathrm{Ni}$ plated part in comparison with $\mathrm{Cu}$ plated and non-plated part (A), optical microscope picture of deposited $\mathrm{Ni}$ on the Schulatec TinCo 50 surface (B).

\section{Roughness analysis of the electroplated surface}

The roughness of the electroplated parts were analysed with the help Alicona and SPIP. The height of the deposited metal was consistently larger but the coverage was less on the surfaces that were not treated. This resulted from the fact of the local concentration of electric fields due to the higher separation between active electrodeposition sites compared to that of the surface treated parts. The highly concentrated and localized plated surface of the non-treated part is visible in Fig. 8 (picture A). The average roughness of non-treated and plated parts was measured $26.2 \pm 2.4 \mu \mathrm{m}$. Compare to this, the treated and plated surface shows more uniformity in the surface profile as shown in Fig. 8 (picture $\mathrm{B}$ and $\mathrm{C}$ for wetblasted and plated with $\mathrm{Cu}$ and $\mathrm{Ni}$ respectively). Nickel plated surface was smother compare to the Copper plated surface The average roughness (Sa) measured on 
the $\mathrm{Ni}$ and $\mathrm{Cu}$ plated parts (5 of each) were $15.8 \pm 2.2 \mu \mathrm{m}$ and $19.7 \pm 2.3 \mu \mathrm{m} \mu \mathrm{m}$ respectively.

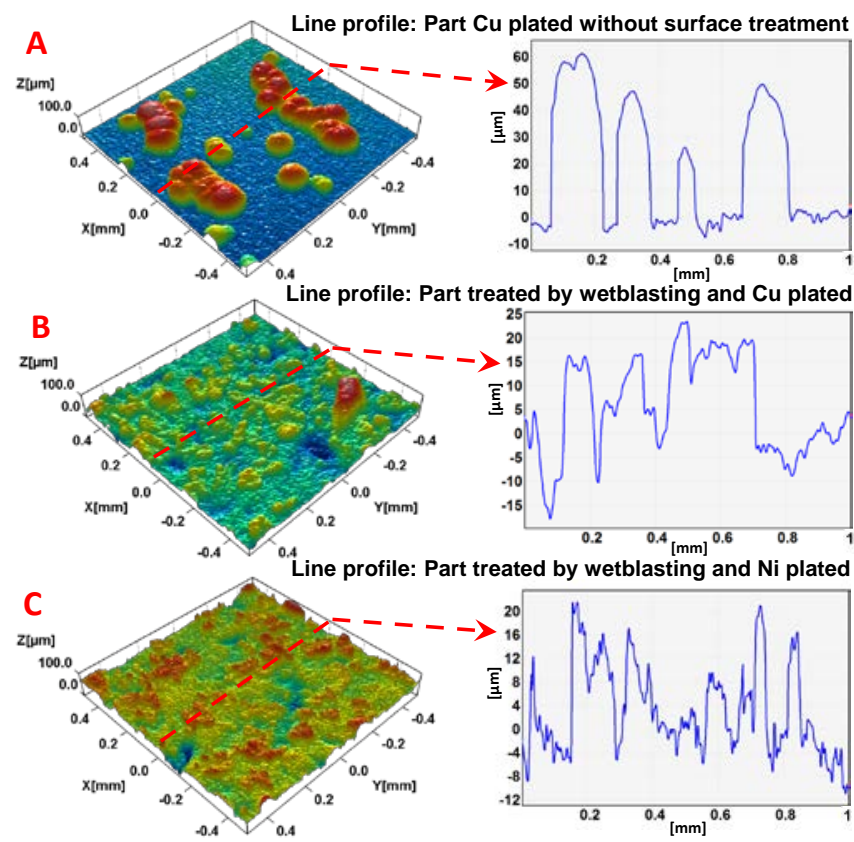

Figure 8. Picture from the electroplated part surface analysis- 3D pictures shows true surface topography and the line profile shows the 2D surface topography along the middle of the image.

\section{Electrical testing}

A simple test setup (Fig. 9-picture A) was made to evaluate the electrical conductivity of the electroplated parts. A significant improvement of the conductivity was observed even with the partially plated surface. For the $\mathrm{Cu}$ plated samples highest conductivity or the lowest volume resistivity was obtained by the electroplating combined with wetblasting process.

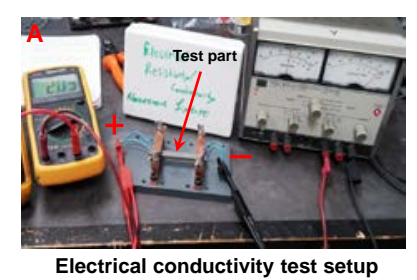

Electrical conductivity test setup

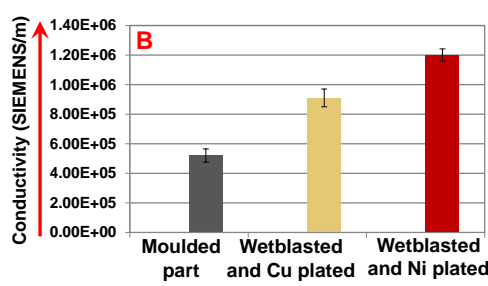

part and Cu plated and Ni plated

Figure 9. Conductivity test setup (A), conductivity test results (B).

About $70 \%$ increase in the conductivity was observed (shown in Fig. 9-picture B) for wetblasted $\mathrm{Cu}$ plated parts. The improvement of the conductivity of the $\mathrm{Ni}$ plated parts (surface treated by wetblasting) was significantly larger. The conductivity measured was about $1.21 \times 10^{6}$ Siemens $/ \mathrm{m}$ which was close to the conductivity of stainless steel an about $140 \%$ increase in conductivity compared with the non-plated parts.

\section{Discussion and future work}

This paper presents the possibility of direct electroplating of plastic materials which already have some degree of conductivity. The electroplating on plastics can bypass many of the known disadvantages of the electroless plating. The skin layer formed during injection moulding proved to be a detrimental factor for electroplating on plastics. In this paper, diverse pre-treatment techniques for the surface were investigated. The best plating results were obtained with the surface treatment by wetblasting. The adhesion was significantly improved by the blasting process and relatively high metal coverage was achieved on wetblasted samples. Future work should be focused on the optimization of the plating process to get $100 \%$ electroplated metal coverage on the surface. In the current work, Schulatec TinCo 50 material was used which was loaded with long copper fibres. Polymer matrix filled with metal particles instead of fibre could have resulted in better plating due to the better dispersion of particles. Various combinations of filler materials like metal fibers, metal particles, carbon nano tubes (CNTs) etc. can be other options for the future investigation. Different plastic matrix should also be investigated in the future other than the currently chosen Polyamide. Moreover the possibilities of chemical etching to remove the skin layer (selectively/non-selectively) should also be investigated.

\section{Conclusion}

A novel method for the direct electroplating of plastic is presented in the paper. It has been demonstrated that the use of conductive plastic composites in direct electroplating can eliminating the need for the state-of-the-art thin layer deposition processes for the electroplating of plastics. Making full coverage of electroplated metal on the plastic surface is a challenge. Different surface treatments like grinding, milling or wetblasting have different levels of influence on the metallic coverage. It is proven that even the partially plated surface can significantly improve the conductivity of the material. After this work, it is possible to add a new MID process chain in the list of available MID manufacturing methods presented in [14], which will be the two component $(2 \mathrm{~K})$ moulding with a conductive/non-conductive plastic pair combined with the subsequent direct electroplating to enhance the conductivity of the electrical structures.

\section{References}

[1] Bakhshi, A., K., Bhalla, G., 2004, Electrically conducting polymers: Materials of the twentyfirst century, Journal of Scientific \& Industrial Research, 63: 715-728.

[2] Hopmann, C., Fragner, J., Haase, S., 2014, Development of electrically conductive plastic compounds based on filler combinations, Journal of Plastics Technology, 2:49-67.

[3] EPRI Technical Report, 1991, Electrically conductive polymers, Materials \& Design, 12/3: 163-165.

[4] Feldmann, K., Gerharda, M., 1995, Direct Soldering of Electronic Components on Molded Devices, CIRP Annals, 44/1: 19-22.

[5] Michaeli, W., Pfefferkorn, T., Fragner, J., 2009, Highly Conductive PlasticsCustom-formulated Functional Materials for Injection Mouldable Electronic Applications, Polymer Electronics - A Flexible Technology, Gardiner, L., F., (Editor), Carter, E., J., (Editor), 43-56.

[6] Merca, T., D., Lindberg, T., Islam, A., 2016, Feasibility study of injection mouldable conductive plastic for the hearing aid applications, Proceedings of 4M/IWMF2016, 11: 677-680.

[7] A. Schulmann GmbH, 2007, Schulatec TinCo 50 Technical Specifications.

[8] Michaeli, W., Hopmann, Fragner, J., Pfefferkorn, T., 2011, Injection molding of conductor paths: integration of functionality by the use of a metal/thermoplastic hybrid material. Journal of Polymer Engineering, 31/6-7:479-487.

[9] Krulik, G., A., 1978, Electroless plating of plastics, Journal of Chemical education, 55/6: 360-370.

[10] Masuku, E., S., Mileham, A., R., Hardisty, H., Bramley, A., N., Johal, C., Detassis, P., 2002, A Finite Element Simulation of the Electroplating Process, CIRP Annals Manufacturing Technology, 51/1:169-172.

[11] Institute of Printed Circuits, 2000, IPC-TM-650, Test Methods Manual.

[12] Okamoto, N., Wang, F., Watanabe, T., 2004, Adhesion of Electrodeposited Copper, Nickel and Silver Films on Copper, Nickel and Silver Substrates, Materials Transactions, 45/12: 3330-3333.

[13] Balseal Engineering, 2003, Metal Plating Processes and Methods of Measuring Surface Hardness and Thickness of Coatings, Technical Report, TR-105, Rev Ø: 15. [14] Islam, A., Hansen, H., N., Tang, P.,T., Jørgensen, M.,B., Ørts, S., F., 2010, Twocomponent microinjection moulding for MID fabrication, Plastics, Rubber \& Composites, 39/7: 300-307. 